\title{
On the cultivation mode of undergradu- ate majoring in agricultural Internet of things
}

\author{
Peng Guo, Naixiang Li \\ Department of Computer Science and Information Engineering, Tianjin Agricultural \\ University, Tianjin, China
}

\begin{abstract}
We analyze demand for talents majoring in Internet of things(IOT) according to current IOT education in China and Chinese development goal of "Twelfth FiveYear Plan" in agricultural field, then we discuss cultivation mode for undergraduate talents and present professional development objective of IOT in agricultural universities, professional teaching methods, training goal and course system are also included in our works.
\end{abstract}

Keywords: Internet of Things; agricultural filed; training mode; course system

\section{Introduction}

As one of the most important application fields of IOT, agricultural IOT combines technologies such as advanced sensor, wireless communications, auxiliary decision support and automatic control. With IOT, users can obtain real-time information of animal and plant growth, plant diseases and insect pests, water and fertilizer condition, they can achieve rational use of agricultural resources, reduce costs, improve environment, increase yield and quality of agricultural products[1]. IOT is promoting development of agriculture to "high yield, highquality, efficient, ecological, safety" stage.
Currently, agricultural IOT application is at initial stage [2]. There are problems such as low level maturity of key technology and lack of professional talents. There is an urgent need to develop training plan for agricultural IOT talent. To speed up education of professional and technical personnel, cooperation among enterprises, universities and academic institutions is needed to advance standardization, industrialization and application of IOT in agricultural field[1].

Because of huge industry demand in China, Chinese Ministry of Education approved the entrance qualification of IOT engineering of 138 universities and colleges[3]. This does not include IOT of computers specialty or communication specialty in many universities. Currently, most universities who educate students majoring in IOT are engineering colleges or comprehensive universities. In 2012, only three agricultural universities have been authorized to teaching undergraduate students majoring in IOT, they are Shandong Agricultural University, Agricultural University of Hebei, Xinjiang Agricultural University. We have learned that training plans and training objectives for IOT students of these agricultural universities are similar to those of engineering colleges or comprehensive universities, being lack of agricultural background knowledge. But agricultural IOT in China is in great demand, the total of 
talent demand in modern agriculture is about 10000000 during "Twelfth FiveYear Plan" [4]. Great talent demand provides a huge market for development of education. Current personnel training of agricultural IOT can not meet the huge demand in Chinese talent market, exploration of talent training pattern in agriculture IOT is of important social significance and practical significance. In this paper, we discuss the industrial demand of talents training mode of agricultural IOT, which includes the orientation of talents training objectives, reform of teaching methods, curriculum and optimization of teaching contents.

\section{Training objectives}

Establishing training objectives is the foundation of higher education, it relates to the direction and target of development of disciplines and specialties and it is the starting point of education and teaching activities[5]. Current application-oriented talents of IOT account for a large proportion. Training plans of IOT in China are generally at experimental stage. Studying and solving the orientation of talents training and training mode of agricultural IOT is urgent to optimization of IOT professionals training and improvement of teaching quality, it is also an important approach to promote development of agricultural information technology.

Application of IOT involves every field in our society, training objective in different fields should be different to meet talent demand of diversity. The orientation of cultivation objectives must be combined with its own characteristics and the needs of social development, they should take different development strategy and form characteristics of their own.

Investigation of IT companies and universities in Tianjin, China shows that emphasis on theory teaching and pay less attention to practice teaching is very common. Although there are plenty of practical courses arranged in education plan, practice contents are chosen from textbook. Practice contents detaching from employers' requirement exist because of authors' knowledge limitations. An experimental environment same as employment can enable students to practise, it can also reduce time to adapt to working condition. How to provide such an environment is an important problem for decision makers of IT education.

Combination of professional knowledge and application knowledge is a trend of engineering teaching, and interdisciplinary talent who masters IOT technology and agricultural knowledge will be favorites in agriculture. For metropolis where there is less agricultural land, development of Peri-urban modern agriculture such as facility planting and smart breeding is a inexorable trend, this rely on agricultural IOT devices and IOT technical staff with agricultural knowledge. Therefore, the orientation of talents training objective should be: Setting the foothold in local community, catering to needs in China to cultivate high-quality talents with all-round development moral qualities, intellectual ability, physical fitness, they should have a good specialty knowledge, agricultural knowledge and humanistic knowledge and dedicate to modern urban agricultural field.

\section{Reform in teaching method}

\subsection{Construction of teaching team}

Research and implementation of teaching methods needs an excellent teaching team, while construction of teaching team needs a good environment. Based on target of high-level personnel training for IT teaching in agricultural universities, department of computer science and information engineering of Tianjin Agricultural University motivate staff in-service ed- 
ucation to improve their abilities of scientific research and engineering practice, which include: (1) Encouraging young teaching staffs to join research teams in famous institutes to strengthen their knowledge accumulation in scientific research, broaden their horizons, improve their scientific literacy. (2) Encouraging young teachers with master degree to study for doctorate and providing necessary support. After learning from doctoral tutors, they accumulate talent training experiences. (3)Encouraging young teachers to take exercise in IOT enterprises, they take part in production and R\&D to improve their ability of practice. After applying what they learned in enterprises to teaching, they enable students to learn knowledge and skills that are consistent with needs of employers. (4)Encouraging teachers to have teacher qualification certificate and engineer certificate. The teacher certificate is a qualified certificate for teachers. Certificate of computer engineer which is obtained after national unified examination is a certificate for teaching staffs who systematically master basic theory, professional technical knowledge and practical experience.

\subsection{Reform in teaching method}

Teaching methods are vital to teaching quality. Currently, the traditional spoonfeeding teaching method is prevalent in colleges and universities, teachers echo what books say and rote learning is popular among students. Some students even rarely study before examination preparation, and they only study in accordance with the outline of reviews from teachers, which result in learning contents being not digested and absorbed and they will forget what they should master soon after examination. It shows that students having past the final examination, but knowledge mastered is not qualified, students' abilities of problem analysis and solving have not been improved, which is a hidden trouble for their personal development. Therefore, it is necessary to change teaching mode from study for exam to improvement of their ability and it is very important to inspire student's enthusiasm and initiative for learning.

The participation type teaching mode should be applied in classroom. When students study chapters relatively easy to understand, teachers and students can implement roles exchange, students explain teaching contents and interact with teachers and other students to realize students' inquiry learning. For contents which can be lively demonstrated, teaching should be implemented in environment similar to working condition, this can enhance students' impression of what they are learning and stimulate them to study harder.

In practice teaching, (1) Encouraging students to participate in the teacher's scientific research, by which students can gradually improve their abilities of handson experience and observation, analysis, problem-solving. (2)To make students know the use of what they are learning, we send them to agricultural IOT institutions to exercise, and this can also provide an opportunity to exercise what they have learned. (3)Encouraging students to take part in scientific contests oriented to university students. By participating in the high level of competition, these students will expand their research horizons, find the gap between them and other students. This can also stimulate their interests of scientific research.

\subsection{Teaching content}

There is a broad prospect of IOT in agricultural field such as environmental information acquisition and control in green house, water-saving irrigation, information monitoring of production environment and vegetative state, smart storage.

To make students have agricultural background knowledge, modern agricul- 
tural technology course should be provided, this can make students understand the general situation and the development trend of farming, fish breeding and poultry raising, agroindustry, agricultural biotechnology, agricultural business management, agricultural information technology. Through studying this course, students should understand fundamental principles in fields mentioned above, which can be good reserves of knowledge for studying agricultural IOT.

The curriculum should be closely combined with practice and application, we make full use of professional application laboratory and teaching base of IOT application to accomplish practice missions. Experiments of information acquisition and control in greenhouse can help improving learning effect because it is of visual effects and impressive. There are confirmatory experiments, comprehensive experiments and innovation experiments in our teaching program, confirmatory experiments demonstrate scientific contents, paying attention to verifying concepts or theories. Comprehensive experiments require students to design experiments and make explanation about their experiments, this can develop students' creative thinking. The purpose of innovative experiments is to improve students ability of innovation. Innovative experiment can make knowledge reservation for students to participate in engineering design competition, guiding them to establish belief engaged in research in the future.

\section{4. curriculum construction}

\subsection{Learning of basic knowledge}

Theoretical knowledge includes general education courses, basic courses in natural science, professional courses, and specialized elective courses. General education courses include courses of litera- ture, history and philosophy, college English and quality education of college students. Studying these courses can promote development of students, form ability of independent thinking and problem solving. Natural science courses include mathematics, electronics and physics. Whether having good foundation of natural science or not directly determines a student's development potential and stamina in scientific research. Professional courses include Introduction to Internet of things, Basis of modern agricultural techniques, Program design with C, Wireless sensor network and RFID technology, embedded system and single chip microcomputer, Internet of things technology and its application, Artificial intelligence. Through studying professional backbone courses, we can make students understand and master basic theory and agricultural background knowledge, establishing overall understanding of IOT in agriculture and obtaining discipline of thinking training. Elective course in major field includes System model of IOT, embedded computing, theory and application of wireless networking, security technology of IOT, networking technology of IOT. After learning elective course, students will have a full understanding of professions and choose suitable research direction according to their actual situations and interests.

\subsection{Practice teaching}

Practice teaching is carried out based on scientific project. We pay attention to training application ability of IOT and combine contents of specific practice with precision agriculture. Practice teachings include: (1)IOT experiments for precision agriculture, through which students study IOT in intelligent greenhouse, build wireless network monitoring platform, collect data and transmitting information of temperature, humidity, $\mathrm{PH}$ value, light and soil nutrient. (2)Management experiment 
in precision agriculture. In this experiment, students mainly study monitoring growth of agricultural products with temperature, chemical and other sensors. Students carry out identifiable real-time data storage and management with RFID label in process of cultivation, production process. (3) Intelligent irrigation experiment. Implementing precision irrigation with high precision soil temperature and humidity sensor, this can make full use of water-saving equipment, optimize scheduling and improve efficiency.

Experiments mentioned above are carried out in outside-school practice base. Combination with aquaculture enterprises can enable student complete experiments of livestock breeding Internet of things, monitoring livestock breeding conditions such as beef cattle, pigs, cows, sheep and building market traceability system to improve breeding efficiency, ensure the safety of meat products. Practice study in experiments can enable students to operate and develop in agricultural environment with professional IOT knowledge they have learned. This can also improve the effectiveness of student learning, and lay the foundation for employment.

\section{Conclusion}

We have presented a paper about education of undergraduate students majoring in Internet of things in agricultural universities. Demand of Talents in modern agriculture in China is great, but current cultivation mode and curriculum does not satisfy requirement. Teaching team construction, teaching methods reform and teaching contents of students majoring in agricultural IOT are included, we have applied our methods to education in Tianjin agricultural university, and results show our methods are effective.

\section{Acknowledgment}

This paper is supported by Tianjin university undergraduate teaching quality and teaching reform research project(C03-0809).

\section{References}

[1] Department of market and economic information, ministry of agriculture. overall plan of IOT applications in agricultural field. http://www.moa. gov.cn/ztzl/xxgzhy/gzbsn/201112/t20 111222_441172. htm

[2] A.Zhu, F. Wang, R. Suo. Application of Internet of things in Chinese modern agriculture. Chinese Agricultural Science Bulletin. pp. 310-314. 2011, 27(02).(in Chinese)

[3] query system of university opening major of Internet of things. http://bbs.iotfans.com/iotedu/

[4] S. Zhang, Y. Wang . Industry talent bottleneck and Countermeasures of Internet of things. China Economic and trade. pp. 77-78. 2012. 14.(in Chinese)

[5] K. Wang, S. Bei, J. Tang. On the mode of cultivating applicationoriented and innovative engineering talents - vehicle engineering specialty as an example, Higher Agricultural Education. pp. 29-32, 2012, 9.(in Chinese) 